- Revista de Iniciação à Docência, v. 5, n. 3, 2020 -

Publicação: março, 2021 - ISSN 2525-4332

\title{
REFLETINDO SOBRE CARACTERÍSTICAS IDENTITÁRIAS DE DOCENTES UNIVERSITÁRIOS, SEUS SABERES E O LÓCUS DE SEU TRABALHO
}

\author{
Matheus Gibbin Zanzini' \\ Jéssica dos Reis Belíssimo ${ }^{2}$ \\ Beatriz S. C. Cortela ${ }^{3}$
}

\begin{abstract}
RESUMO: O artigo traz reflexões teóricas acerca de características identitárias de docentes universitários, seus saberes e o lócus de seu trabalho. Mais especificamente, tratamos de reflexões sobre aspectos relativos às universidades públicas e sobre os profissionais que atuam com a formação inicial de professores. Para tanto, são apresentados quatro modelos de universidade predominantes no mundo, que determinam as suas funções sociais; são apontadas características das identidades profissionais docentes no ensino superior, sendo essas decorrentes do modo de organização das instituições, de teorias da aprendizagem e de teorias sobre formação de professores. Os estudos e reflexões realizadas apontam que as características identitárias, em relação às universidades, se expressam no tripé pesquisa, ensino e extensão, acrescido de aspectos de gestão. Quanto aos aspectos identitários dos docentes, identificamos que são fortemente marcados pela individualidade e o predomínio da identidade profissional de pesquisador em detrimento da de professor.
\end{abstract}

Palavras-Chave: Função Social; Universidade; Docência; Ensino Superior.

ABSTRACT: This article brings theoretical reflections on the identity characteristics of university professors, their knowledge and the locus of their work. More specifically, reflections on aspects related to public universities and on professionals who work with initial teacher training. For that, four models of university predominant in the world are presented, which determine their social functions; characteristics of the professional identities of teachers in higher education are pointed out, which are due to the way in which institutions are organized, theories of learning and theories about teacher training. The studies and reflections carried out show that the identity characteristics, in relation to the universities, are expressed in the research, teaching and extension tripod, in addition to management aspects. As for the identity aspects of teachers, these are strongly marked by individuality and the predominance of the professional identity of the researcher to the detriment of that of the teacher.

Key Words: University Social Function; Teaching; Higher Education; Teacher Training.

\section{Introdução}

Um evento 4 promovido por uma universidade pública brasileira de excelência, em 2018, teve o objetivo de debater os rumos dessa instituição de ensino superior frente à atual situação política do país à época, apontando que os desafios a serem enfrentados eram de ordem financeira e de identidade institucional.

\footnotetext{
${ }^{1}$ Doutorando do Programa de Pós-Graduação em Educação para a Ciência (UNESP-Bauru).

2 Doutoranda do Programa de Pós-Graduação em Educação para a Ciência (UNESP-Bauru).

3 Docente. Departamento de Educação, Faculdade de Ciências, Universidade Estadual Paulista (UNESPBauru). E-mail: <beatriz.cortela@unesp.br>.

4 Palestra proferida pelo Prof. Dr. Simon Schwartzman, em evento promovido pela Escola de Liderança e Gestão da Universidade Estadual Paulista (UNESP), no dia 21 de novembro de 2018.
} 
Quanto aos desafios referentes ao financiamento, que não corresponde ao foco das reflexões deste artigo, consistem em um emaranhado de aspectos, desde a necessidade de novas contratações, quanto aqueles referentes às despesas salariais e decorrentes das aposentadorias, financiamento de pesquisas, questões de infraestrutura, entre outros aspectos. Além disso, na atualidade, as universidades públicas brasileiras enfrentam uma tentativa de desmanche em decorrência de severos cortes de verbas e financiamentos, o que pode comprometer sua atuação futura. Sofrem também ataques por meio da proliferação de discursos governamentais e midiáticos equivocados, que visam desqualificar os docentes, alunos e a pesquisa nacional.

As reflexões apresentadas neste artigo visam discutir características identitárias de universidades e de seus docentes. Em um primeiro momento, a universidade é debatida quanto a sua função social, com base em alguns modelos organizativos consolidados historicamente. Na sequência, são apresentadas algumas características das identidades de seus docentes, tendo como base a organização institucional e teorizações nacionais e internacionais. Por fim, são apresentadas reflexões sobre a formação inicial de professores no Brasil.

\section{Refletindo sobre a função social das universidades}

Para se compreender a função social das universidades e, assim, suas identidades, faz-se necessário estudar os diferentes modelos institucionais com base nos quais essas instituições estão estruturadas. Segundo a literatura especializada, as universidades atuais podem ser compreendidas a partir três modelos clássicos (SOUZA et al., 2013), e mais um surgido no final do século XX nos países europeus e em atual expansão no contexto dos países do ocidente (MACEDO, 2017).

O primeiro deles, conhecido como napoleônico por ter sido institucionalizado na França no início do século XVIII, consiste em um modelo com perspectiva funcionalista, no qual a função social da universidade é, principalmente, a formação das pessoas para exercerem atividades de trabalho na sociedade, e, em menor medida, também a produção de conhecimentos. Nele há uma segmentação entre as instâncias que promovem o ensino e a pesquisa, de maneira que as atividades de ensino recebem primazia.

O segundo modelo, conhecido como humboldtiano, desenvolvido por Alexander Von Humboldt e adotado pela Universidade de Berlin em meados do século XVIII, permite maior autonomia de gestão das universidades em relação às instâncias externas, tais como o Estado, a Igreja e o mesmo ao setor privado. Nele, influenciado pelo positivismo, a pesquisa acadêmica corresponde à principal função social das universidades.

O terceiro, conhecido como americano, desenvolvido no século XIX nos Estados Unidos da América, consiste em uma mescla dos dois modelos anteriores e se amplia, desenvolvendo também atividades extensionistas na forma de prestação de serviços à comunidade, e também, visando a captação de financiamento de fontes privadas externas 
à universidade, de maneira a ajustar os objetivos da Educação Superior às demandas da sociedade de consumo.

Durante o final da década de 1990, debates ocorridos na Europa culminariam, em 1999, na elaboração de diretrizes para as instituições de ensino superior que ficaram conhecidas como Tratado de Bolonha. Este vem se configurando como o quarto modelo de universidade e está presente em todos os países da União Europeia (MACEDO, 2017). Ele visa unificar os sistemas de ensino superior dos países envolvidos, por meio de um sistema comum de creditação (European Credit Transfer and Accumulations System), facilitando a mobilidade discente e docente entre as instituições de ensino superior.

Esse tratado também objetiva reduzir o tempo de formação, configurando o ensino superior em três níveis consecutivos e independentes, os quais, frequentemente acontecem em espaços físicos distintos. O primeiro, com duração de três a quatro anos, envolve uma formação mais ampla, permitindo aos estudantes transitar por múltiplas áreas, conferindo-lhes o direto de exercerem atividades de trabalho que, no Brasil, não necessitam desse nível de escolarização. O segundo, com duração de mais um ou dois anos, corresponde a estudos especializados, equivalente ao mestrado brasileiro, e que permite o exercício de profissões, tais como as Engenharias, Medicina, Direito, entre outras. Por fim, o terceiro, com duração de mais três ou quatro anos, confere título equivalente ao doutorado brasileiro e é destinado àqueles que irão realizar pesquisas acadêmicas e/ou atuar como docentes no ensino superior.

As universidades brasileiras, jovens em relação às europeias e estadunidenses, foram influenciadas pelos primeiros três modelos anteriormente descritos, mas efetuando modificações gerando, assim, modelos híbridos em parte das instituições (SOUZA et al., 2013). Esse hibridismo se observa no fato de a universidade pública brasileira focar atenção, principalmente, em aspectos que se aproximam do modelo humboldtiano, priorizando a pesquisa, e, em menor grau o ensino, e aspectos que se aproximam do modelo americano, que visa atender às demandas da sociedade capitalista por meio da extensão. De maneira híbrida ou mais homogênea, os modelos mencionados estão presentes na estrutura das universidades nacionais há pelo menos 60 anos.

Dessa maneira, observa-se que as características identitárias das universidades públicas nacionais estão moldadas no denominado tripé pesquisa, ensino e extensão, normalmente nesta ordem de prioridade, predominando amplamente a pesquisa. Em perspectiva para o futuro, cabe o questionamento sobre como o movimento europeu, simbolizado pelo Tratado de Bolonha, influenciará (ou não) as universidades brasileiras. A adoção deste modelo, ou alguma forma híbrida deste, pode resultar em instituições que apenas realizem o ensino e outras onde ocorram somente as pesquisas. Em busca da internacionalização, possivelmente, os gestores universitários terão que decidir qual ou quais dos três níveis de ensino superior irão priorizar e ofertar, acarretando mudanças nas identidades das universidades nacionais, a partir da função social a ser adotada. 


\section{Características identitárias de docentes universitários: um debate a partir da influência institucional e das teorias de ensino e da aprendizagem}

Para que as universidades públicas brasileiras atendam às suas funções de realizarem pesquisa, ensino e extensão, com qualidade, são traçadas metas institucionais a serem atingidas pelos docentes. Desde 1968 (Lei 5540/68)5, a organização institucional das universidades públicas nacionais passou a ser por departamentos específicos, como o de Química, de Física, de Psicologia e de Educação, entre outros, substituindo as antigas cátedras. Porém, as funções a serem desenvolvidas ainda continuam sendo de responsabilidade individual de cada docente. Ou seja, cada um deve contabilizar periodicamente um montante de pontos por meio de atividades de pesquisa, ensino e extensão. Além dessas, também são contabilizadas atividades de gestão institucional (chefias e conselhos de departamentos, participação em comissões e colegiados, entre outras), e também a capacidade de conseguir financiamento para pesquisas e atividades acadêmicas, que Zabalza (2005) chama de business.

As disciplinas ofertadas em cada curso superior são ministradas por docentes de diferentes departamentos, o que também dificulta a atuação coletiva deles, mas pode favorecer a interdisciplinaridade. Isso pode ser evidenciado em casos de reestruturações curriculares, como no caso de cursos de licenciatura (CAMARGO, 2007; CORTELA, 2011), onde, em grande medida, cada docente busca garantir a continuidade da disciplina que leciona, sem se engajar em uma compreensão mais ampla do curso em questão. Assim, tais docentes apresentam características identitárias de especialista em determinada área acadêmica (na qual realizam suas pesquisas), e, em menor medida, de professores (em muitos casos apenas para satisfazerem as exigências da carreira profissional do ensino superior).

Os últimos argumentos evidenciam a principal característica das identidades profissionais dos docentes universitários, que é a individualidade, tanto no tocante ao ensino quanto à pesquisa. Com a intenção de superá-la, defende-se aqui a possibilidade de serem contabilizadas atividades coletivas (de membros de um departamento, docentes de um curso, entre outros) no comprimento das metas individuais. Ou seja, que as atividades de pesquisa, ensino, extensão e gestão sejam planejadas e realizadas por grupos de docentes, coletivamente.

Outra característica das atividades de trabalho dos docentes universitários no Brasil, e em outros países como Portugal e Espanha, decorre da ampliação de vagas no ensino superior ocorrida nas últimas décadas. Isso causou aumento e diversificação do contingente de estudantes universitários. Ao se traçar um panorama do ensino superior brasileiro entre os anos de 2000 e 2018, verifica-se um aumento significativo no número de instituições e de alunos matriculados. Conforme os dados do Censo da Educação Superior,

\footnotetext{
${ }^{5}$ Fixou, à época, normas de organização e funcionamento do ensino superior e sua articulação com a escola média, dando outras providências. https://presrepublica.jusbrasil.com.br/legislacao/109783/lei-5540-68
} 
em 2000, existiam 1.180 instituições (176 públicas e 1.004 privadas) e 2.694.245 alunos matriculados (887.026 em instituições públicas e 1.807.219 em privadas). Já em 2018, tais números subiram para 2.537 instituições (299 públicas e 2.238 privadas), e 8.450 .755 alunos matriculados (2.077.481 em instituições públicas e 6.373.274 em privadas).

O expressivo aumento dos números relacionados às instituições privadas decorre de políticas federais de acesso e permanência estudantil no ensino superior, adotados a partir do governo Lula. Se, por um lado, tais investimentos beneficiam muitos alunos e suas famílias, por lhes permitir estudar em instituições de ensino superior e uma suposta ascensão social, por outro, possivelmente beneficiam ainda mais os proprietários das instituições privadas, que recebem os subsídios do Estado para seus negócios.

Dessa forma, os docentes do ensino superior estão sendo chamados a se adaptarem às mudanças institucionais, relacionadas principalmente ao novo contingente estudantil e às novas tecnologias da informação e da comunicação. Essas últimas causam rápida expansão do acesso das pessoas às informações, que resultam, em muitos casos, na aquisição de conhecimentos de qualidade duvidosa. Assim, o montante de informações que os estudantes têm hoje é mais amplo do que o de gerações anteriores, possibilitando a proliferação de concepções cientificamente equivocadas. Então, cabe aos docentes universitários lidarem com essa realidade, no intuito de suprir as lacunas nas informações e realizar as devidas correções conceituais.

Esse novo cenário do ensino superior traz a necessidade de debater os conteúdos e as disciplinas a serem ofertadas em cada curso, bem como, as metodologias de ensino utilizadas pelos docentes. O que se espera dos docentes universitários (ZABALZA, 2005) é que tenham uma dupla competência: a científica, como conhecedores de áreas acadêmicas específicas, e a pedagógica, que consiste no domínio plural de metodologias de ensino, juntamente com um sério compromisso com a aprendizagem de seus alunos.

Portanto, a compreensão de como os alunos aprendem não só se faz necessária, como também deveria subsidiar as práticas didáticas dos docentes da universidade e da Educação Básica. Entre as clássicas teorizações da literatura especializada sobre a aprendizagem, os modelos baseados em mudança conceitual, predominantes na área de Ensino de Ciências da Natureza até meados dos anos 1990, oferecem contribuições relevantes para as atividades didáticas. Em suma, tais modelos defendem que as concepções alternativas/prévias dos alunos influenciam suas aprendizagens futuras, e, portanto, precisam ser conhecidas antecipadamente pelos professores com vistas a serem modificadas.

O conjunto de conhecimentos que o aluno traz consigo, oriundo de outros espaços e tempos de vivências, forma um arcabouço cognitivo compreendido como sendo a sua ecologia conceitual (POSNER et al., 1982). Mediante processos de assimilações e acomodações, tal arcabouço pode sofrer modificações. Os processos de assimilação são aqueles em que novas informações são apropriadas pelos indivíduos, o que pode resultar 
em conflitos cognitivos em sua ecologia conceitual, causando insatisfação, ou seja, o reconhecimento do sujeito de que os conhecimentos que dispõem não são suficientes para satisfazerem as necessidades da situação/problema em questão.

Nesse caso, a ecologia conceitual pode ser modificada pelas novas informações que forem apropriadas. Para que isso ocorra, essas devem ser inteligíveis e plausíveis, ou seja, compreensíveis e coerentes a alguns outros conhecimentos de domínio prévio do sujeito. Também devem ser frutíferas, ou seja, devem apresentar potencialidade de serem utilizadas em situações futuras pelo aprendiz. Satisfeitos esses quatro aspectos, é grande a probabilidade de ocorrer uma modificação na ecologia conceitual do indivíduo, denominada de mudança conceitual. A modificação no arcabouço cognitivo do sujeito resulta em um estado de ecologia conceitual que engloba as novas informações, processo que pode ocorrer de maneira rápida ou lenta, e é denominado de acomodação.

A partir das décadas de 1980 e 1990, o modelo de mudança conceitual influenciou fortemente a área de pesquisa em Ensino e em Educação em Ciências (CARVALHO et al., 1992), sendo realizadas diversas investigações acadêmicas visando compreender quais são as concepções prévias que os estudantes sustentam a respeito de diversos conteúdos ensinados na escola. Tais pesquisas proliferaram de modo que, atualmente, áreas como a de ensino de Física e a de ensino de Química dispõem de vasta quantidade de resultados de pesquisa a esse respeito, tendo possivelmente atingido a saturação em relação a diversos dos conteúdos da Educação Básica. Porém, paradoxalmente, tais resultados ainda são pouco utilizados pelos docentes nos cursos de licenciatura, os quais continuam bastante tradicionais em suas atividades didáticas (CORTELA; NARDI, 2015).

Ainda durante a década de 1990, o modelo de mudança conceitual foi alvo de diversas críticas (ARRUDA; VILLANI, 1994), relacionadas à necessidade de se romper com a linearidade do processo (a sequência dos quatro aspectos necessários para se alcançar as acomodações) e de se levar em consideração processos de aprendizagem que não sejam conflitivos cognitivamente para os alunos. Além disso, criou-se a ilusão de que os professores poderiam substituir as concepções prévias dos alunos, sendo que elas são, na maioria das vezes, apenas modificadas por eles. Assim, correr-se-ia o risco de que o ensino baseado em mudança conceitual fosse reduzido simplesmente às tentativas de diminuir a validade das concepções prévias dos alunos, por meio de comparações com as concepções dos professores, gerando uma nova versão do tradicionalismo pedagógico.

No final da década de 1990, um modelo mais amplo de aprendizagem é proposto na literatura especializada, o qual ficou conhecido como Perfil Conceitual (MORTIMER, 1996). Nele, o indivíduo possui mais do que uma concepção em seu arcabouço cognitivo para um mesmo fenômeno ou conteúdo escolar. Nas diversas relações sociais estabelecidas nas vivências dos indivíduos, eles ponderam sobre qual concepção será utilizada no contexto em questão. 
Outros modelos de aprendizagem importantes para os docentes universitários são aqueles baseados na metacognição e na andragogia, em especial considerando a faixa etária dos alunos (RIBEIRO, 2003). É recorrente certa confusão sobre a definição do termo metacognição devido, principalmente, a sua ampla utilização pela Psicologia, onde diversas perspectivas deram origem a diferentes definições. Sugere-se, aqui, que a metacognição esteja relacionada ao conhecimento do próprio ato de aprender, no sentido de tomadas de consciência sobre os próprios processos cognitivos. Ela está relacionada à demanda de reflexão sobre o próprio modo de pensar e aprender.

No que se refere à andragogia, pode ser definida como o estudo sobre processos de aprendizagem envolvendo aprendizes adultos. Visando obter bons resultados nos processos de ensino, os docentes devem estabelecer relações horizontais com seus alunos (de adulto para adultos), as quais devem ser caracterizadas pelo diálogo, pela informalidade e pela colaboração.

$\mathrm{Na}$ perspectiva de educação andrológica, os sujeitos devem participar das diversas fases do processo de ensino, que parte do diagnóstico de necessidades educativas, passando pela elaboração de planos, o estabelecimento de objetivos e as definições das formas de avaliações (NOFFS; RODRIGUES, 2011, p. 286).

Nesse sentido, os docentes devem assumir papel de mediadores das relações envolvendo os alunos e os conteúdos programáticos estabelecidos para a disciplina em questão. Cabe aos docentes incentivar os alunos de forma que eles desenvolvam estratégias individuais para o enfrentamento de determinada situação/problema e sejam levados a buscar soluções e a refletir sobre suas escolhas (RIBEIRO, 2003).

Nos modelos de aprendizagem apresentados anteriormente são coerentes a utilização de metodologias como a de ensino investigativo, o ensino baseado na resolução de problemas e o ensino baseado em projetos. Também a utilização de mapas conceituais é uma estratégia pedagógica útil, além de ser um bom instrumento de avaliação (GALANTE, 2013). Com a utilização de mapas conceituais, os docentes incentivam os alunos a planificar e organizarem as informações que estão sendo tratadas, favorecendo os processos metacognitivos. Para isso, os alunos devem relacionar conceitos por meio de setas e verbos de ligação expressando, assim, seus pensamentos de modo esquemático.

Em face da realidade contemporânea, é importante que aspectos sociocientíficos, ambientais e tecnológicos permeiem qualquer metodologia de ensino utilizada nas universidades, e, também, na educação básica. Reitera-se, assim, a sugestão de que os docentes do ensino superior devem adotar uma pluralidade metodológica em suas atividades didáticas.

Coerentemente, os docentes devem realizar escolhas referentes aos processos avaliativos que utilizam. Assim, sugere-se que optem por processos de avaliação formativa (MENDES, 2005), a qual deve ocorrer durante todo o processo de ensino, de modo que o conceito final obtido pelo aluno seja uma consequência natural de sua participação e aprendizado no decorrer do semestre letivo. 


\section{Refletindo sobre os formadores de professores.}

A formação de professores pode ser compreendida em duas acepções (GARCIA, 1999; MIZUKAMI et al., 2002; MONTERO, 2005). Uma delas é referente à prática social situada no sentido de formar pessoas para exercerem as atividades de trabalho como professores na educação básica. A outra é referente às pesquisas acadêmicas realizadas, principalmente no âmbito das áreas de Ensino e de Educação, que focam aspectos pertinentes à formação e atuação profissional dos professores.

Enquanto prática social situada, a formação de professores começou a ser realizada na Europa durante o século XVI, mas foi a partir da segunda metade do século XX que efetivamente passou a ocorrer em países ocidentais. O crescimento quantitativo dessa prática social foi causado pela expansão da oferta de escolarização ocorrida em vários países (incluindo o Brasil) nos últimos 50 anos, o que aumentou a demanda por professores que atuam na escola básica.

No Brasil, os cursos de licenciatura devem ser oferecidos em instituições de ensino superior e devem seguir as Diretrizes Curriculares Nacionais para a Formação de Professores da Educação Básica, as quais são expressas em documentos normativos com considerável frequência de alteração a partir dos anos 2000. Definidas pelo Conselho Nacional de Educação, às primeiras diretrizes do século XXI foram promulgadas em 2002 (BRASIL, 2002), sendo substituídas por novo documento normativo em 2015 (BRASIL, 2015); e por outro em 2019 (BRASIL, 2019). Isso acarretou a necessidade de as instituições de ensino superior reestruturarem os cursos de formação inicial, não somente em relação às cargas horárias, como também aos modelos formativos adotados, superando a racionalidade técnica em favor da prática, inicialmente, indo em direção à crítica e, agora, num retrocesso, ao que a literatura chamada de neobehaviorismo.

Em dezembro de 2019, o Conselho Nacional de Educação novamente alterou as diretrizes, promulgando nova resolução, a qual institui a Base Nacional Comum para a Formação Inicial de Professores da Educação Básica. Essa resolução visa alinhar a formação inicial às novas políticas educacionais brasileiras para a Educação Básica (Base Nacional Comum Curricular e Reforma do Ensino Médio). Esse recente documento normativo já é alvo de críticas de acadêmicos e de organizações como a Associação Nacional pela Formação dos Profissionais da Educação (ANFOPE). Assim, os cursos de formação inicial são novamente solicitados a realizarem processos de reestruturação curricular. Eles têm o prazo de dois anos para isso, com exceção daqueles que já haviam se reestruturado em relação às diretrizes de 2015, que possuem o prazo de três anos para a nova adequação. A duração mínima dos cursos foi mantida, totalizando 3.200 horas, sendo essa carga horária assim distribuída:

Grupo I: 800 horas para a base comum que compreende os conhecimentos científicos, educacionais e pedagógicos e fundamentam a educação e suas articulações com os sistemas, as escolas e as práticas educacionais. 
Grupo II: 1.600 horas para a aprendizagem dos conteúdos específicos das áreas, componentes, unidades temáticas e objetos de conhecimento da BNCC, e para o domínio pedagógico desses conteúdos.

Grupo III: 800 horas de prática pedagógica, assim distribuídas:

a) 400 horas para o estágio supervisionado, em situação real de trabalho em escola, segundo o Projeto Pedagógico do Curso da instituição formadora; e

b) 400 horas para a prática dos componentes curriculares dos Grupos I e II, distribuídas ao longo do curso, desde o seu início (BRASIL, 2019, p. 6).

Todo curso de formação de professores deve possibilitar o aprendizado de um conjunto de conhecimentos que permita aos egressos exercerem competentemente as atividades de trabalho dos professores da Educação Básica. Na literatura especializada, tal conjunto ficou conhecido pelo rótulo de saberes docentes, havendo um vivo debate sobre quais são os tipos de conhecimentos que o compõem. Atualmente, diversas tipologias coexistem, as quais são teorizações úteis (TERRAZZAN et al., 2008), termo utilizado pelo autor, para a proposição de ementas e de conteúdos a serem tratados durante as disciplinas ofertadas em cursos de licenciatura.

O Grupo de Estudos, Pesquisas e Intervenções "Inovação Educacional, Práticas Educativas e Formação de Professores”, tendo como principal contribuição as teorizações propostas por Lee S. Shulman (SHULMAN, 1986; 1987) e por Clermont Gauthier e colaboradores (GAUTHIER et al., 2013), sugere que os saberes docentes necessários para a atuação enquanto professores da Educação Básica são de cinco tipos: conhecimento referente à matéria de ensino; conhecimento pedagógico amplo; conhecimento didático referente à matéria de ensino; conhecimento dos contextos educacional e escolar; conhecimento sobre a profissão e a profissionalização. Esses tipos de conhecimento, com exceção daqueles referentes à profissão e profissionalização, foram constatados em cursos de licenciatura em Química de universidades públicas de excelência (ZANZINI; TALLES; TERRAZZAN, 2015).

Outro tipo de tipologia de saberes docentes se refere aos conhecimentos sugeridos como necessários para os docentes universitários. Uma proposição desse outro tipo de tipologia expressa oito competências (ZABALZA, 2005), sendo elas, a capacidade de: planejar o processo de ensino e aprendizagem; selecionar e apresentar os conteúdos de uma disciplina; oferecer informações e explicações compreensíveis aos alunos; gerenciar atividades envolvendo diferentes metodologias de ensino; se relacionar harmonicamente com os alunos; atualização de tecnologias; tutorear os alunos; reflexão sobre suas atividades de ensino; e, a capacidade de atuar politicamente junto à instituição.

Diante do exposto, alguns questionamentos surgem: há diferenças entre os saberes docentes para os professores que irão atuar na Educação Básica e os que irão atuar em cursos de formação inicial? Um conjunto é mais amplo do que o outro ou consistem em tipos diferentes de conhecimentos? As tipologias referentes ao ensino universitário devem englobar conhecimentos necessários para realizar competentemente atividades de 
pesquisa e de extensão? Para tais questionamentos ainda não há consenso, de modo que as identidades profissionais dos formadores de professores ainda não têm contornos bem determinados.

Para finalizar, são sugeridas ações a serem desenvolvidas em âmbito institucionais, ou ainda de responsabilidade de cada curso e/ou departamento, as quais podem contribuir para o constante aperfeiçoamento dos docentes do ensino superior. Na Espanha, como, por exemplo, nas universidades de Sevilla, Politécnica de Valência e de Santiago de Compostela, se constatam processos de formação docente em serviço realizada entre pares acadêmicos, que consistem em tutorias dos mais experientes aos menos experientes (ZABALZA, 2005).

Também na Espanha se desenvolvem ações institucionais na forma de estudos sistemáticos das aulas ministradas, produzindo um acervo a ser compartilhado entre os docentes. Outro exemplo ocorre na Universidade Politécnica da Cataluña, que oferece reconhecimento aos docentes que comentam livros, disponibilizando esses comentários aos alunos e ao público em geral. Mais um exemplo ocorre na Universidade Autónoma de Barcelona, onde cada docente pode ficar responsável por resenhar algum tema de interesse acadêmico, que será compartilhado entre os alunos.

Tais ações apresentam caráter inovador no contexto brasileiro, visto que elas ainda não ocorrem nas universidades nacionais de maneira institucionalizada. Assim, a exemplo dos processos de formação continuada vivenciados pelos professores da Educação Básica, uma questão merecedora de atenção consiste no desenvolvimento de processos de aperfeiçoamento em serviço para os docentes universitários. Dessa maneira, cabe o questionamento sobre quais seriam os modelos adequados para esses processos de aperfeiçoamento; quem seriam os responsáveis por eles, e como seriam contabilizados nas metas dos docentes. Algumas universidades públicas já desenvolvem este tipo de formação, tal como a Universidade Estadual Paulista (UNESP), a Universidade de São Paulo (USP), a Universidade do Estadual da Bahia (UNEB), entre outras.

\section{Considerações finais}

Neste artigo, buscamos compartilhar reflexões, com base na literatura especializada, visando contribuir para o delineamento de possíveis identidades no âmbito do ensino superior, mais especificamente, aquelas relacionadas à instituição de ensino superior público, aos docentes universitários e aos cursos de formação inicial de professores.

No caso das características identitárias das universidades brasileiras, elas derivam de suas funções sociais. Tais funções sociais, atualmente, estão baseadas em três modelos clássicos de universidade: o napoleônico, o humboldtiano e o americano. Destaca-se que tais modelos não ocorrem em sua forma pura e original, mas sim de maneira híbrida, variando devido às intenções políticas e ao contexto de cada instituição. Mais recentemente, em algumas instituições de ensino superior de excelência, busca-se atender 
também às demandas da internacionalização. Nesse contexto, em breve, provavelmente o Tratado de Bolonha começará a influenciar as instituições de ensino superior brasileiras, o que pode acarretar processos de reestruturação dessas instituições universitárias.

No tocante as características das identidades profissionais dos docentes no ensino superior, elas estão diretamente relacionadas à função social da universidade à qual eles estão vinculados. Como corroborado por Almeida (2012), no caso da maioria das universidades particulares, o foco da atuação docente está no ensino, na extensão e na pesquisa, nesta ordem. Enquanto, no caso das instituições públicas, o foco está na pesquisa, no ensino e na extensão, nesta ordem. Apesar dos contornos mal definidos dessas identidades, elas se caracterizam pela predominância da individualidade. Mesmo nos poucos projetos coletivos, os docentes se agrupam por suas características individuais, baseadas na meritocracia, com fortes condicionantes atrelados às publicações acadêmicas e ao levantamento de financiamento junto às instituições de fomento públicas e privadas.

Por fim, no tocante as identidades profissionais dos formadores de professores, suas características são resultantes de uma composição de forças exercidas pelos próprios docentes que atuam em cada curso. Provenientes de diferentes departamentos, os docentes dos cursos de licenciatura buscam manter seus ideais formativos, interesses profissionais e o modo que lecionam, de forma que poucos se engajam no objetivo central do curso: formar professores para a Educação Básica.

\section{Referências}

ALMEIDA, M. I. Formação do professor do Ensino Superior: desafios e políticas institucionais. São Paulo/SP: Cortez, 2012.

ARRUDA, S. M.; VILLANI, A. Mudança Conceitual no Ensino de Ciências. Caderno Catarinense de Ensino de Física, v. 11, n. 2, 1994, p. 88-99.

BRASIL. Ministério da Educação. Conselho Nacional de Educação. Resolução CNE/CP 01/2002. Institui as Diretrizes Curriculares Nacionais para a Formação de Professores da Educação Básica, em nível superior, curso de licenciatura de graduação plena. Brasília/DF: MEC/CNE, 2002. Disponível em: http://portal.mec.gov.br/cne/arquivos/pdf/rcp01_02.pdf. Acesso em 19 jun. 2020.

BRASIL. Ministério da Educação. Conselho Nacional de Educação. Resolução CNE/CP 02/2015. Define as Diretrizes Curriculares Nacionais para a formação inicial em nível superior (cursos de licenciatura, cursos de formação pedagógica para graduados e cursos de segunda licenciatura) e para a formação continuada. Brasília/DF: MEC/CNE, 2015. Disponível em: http://portal.mec.gov.br/docman/agosto-2017-pdf/70431-res-cne-cp-002-03072015-pdf/file. Acesso em: 19 jun. 2020.

BRASIL. Resolução CNE/CP 02/2019. Define as Diretrizes Curriculares Nacionais para a Formação Inicial de Professores para a Educação Básica e institui a Base Nacional Comum para a Formação Inicial de Professores da Educação Básica (BNC-Formação). Brasília/DF: MEC/CNE, 2019. Disponível em: http://portal.mec.gov.br/docman/dezembro-2019-pdf/135951-rcp002-19/file. Acesso 19 jun. 2020. 
CAMARGO, S. Discursos presente em um processo de reestruturação de um curso de licenciatura em física: o legal, o real e o possível. 2007. Tese (Doutorado em Educação para a Ciência) - Faculdade de Ciências, Universidade Estadual Paulista, Bauru/SP, 2007.

CARVALHO, A. M. P. et al. Pressupostos epistemológicos para a pesquisa em ensino de ciências. Cadernos de Pesquisa, v. 82, p. 85-89, 1992.

CORTELA, B. S. C. Formação inicial de professores de física: fatores limitantes e possibilidades de avanços. 2011. Tese (Doutorado em Educação para a Ciência) Faculdade de Ciências, Universidade Estadual Paulista, Bauru, 2011.

CORTELA, B. S. C.; NARDI, R. A constituição de um perfil identitário de um curso de Física. In: NARDI, R.; CORTELA, B. S. C. (Org.). Formação inicial de professores de Física em Universidades Públicas: estudos realizados a partir de recentes reestruturações curriculares. São Paulo/SP: Livraria da Física, 2015, p. 99-132.

GALANTE, C. E. S. O Uso de mapas conceituais e de mapas mentais como ferramentas pedagógicas no contexto educacional do Ensino Superior. Revista Eletrônica Saber, Londrina/PR, v. 23, 2013.

GARCIA, C. M. Formação de professores: para uma mudança educativa. Porto: Porto Editora, 1999.

GAUTHIER, C. et al. Por uma teoria da pedagogia: pesquisas contemporâneas sobre o saber docente. ljuí/RS: Editora Unijui, 2013.

MACEDO. B. O processo de Bolonha: discursos e dinâmicas da reformulação educacional nas universidades da União Europeia. Debater a Europa, v. 16, 2017, p. 209-219.

Disponível em: https://impactum-journals.uc.pt/debatereuropa/article/view/_16_9/3717. Acesso em: 15 jun. 2020.

MENDES, O. M. Avaliação formativa no ensino superior: reflexões e alternativas possíveis. In: VEIGA, I. P. A.; NAVES, M. L. P. (Org.). Currículo e avaliação na educação superior. São Paulo/SP: Junqueira \& Marin, 2005, p. 175-197.

MIZUKAMI, M. G. N. et al. Escola e aprendizagem da docência: processos de investigação e formação. São Carlos/SP: EdUFSCar, 2002.

MONTERO, L. A construção do conhecimento profissional docente. Lisboa: Instituto Piaget, 2005.

MORTIMER, E. F. Construtivismo, Mudança Conceitual e ensino de Ciências: para onde vamos? Investigações em Ensino de Ciências, v. 1, n. 1, 1996, p. 20-39.

NOFFS, N. A.; RODRIGUES, C. M. R. Andragogia na Psicopedagogia: a atuação de adultos. Revista Psicopedagogia, v. 28, n. 87, 2011, p. 283-292, 2011. Acesso em: 15 jun.2020. Disponível em: http://pepsic.bvsalud.org/scielo.php?script=sci_arttext\&pid=S0103-84862011000300009\&lng=pt\&nrm=iso.

POSNER, G. J. et al. Accomodation of a Scientific Conception: Toward a Theory of Conceptual Change. Science Education, v. 66, n. 2, 1982, p. 211-227. 
RIBEIRO, C. Metacognição: um apoio ao processo de aprendizagem. Psicologia: Reflexão e Crítica, Porto Alegre/RS, v. 16, n. 1, 2003, p. 109-116.

Disponível em: https://www.scielo.br/pdf/prc/v16n1/16802.pdf. Acesso em: 15 jun. 2020.

SHULMAN, L. S. Knowledge and teaching: foundations of the new reform. Harvard Educational Review, Cambridge, v. 57, n. 1, 1987, p. 1-22.

SHULMAN, L. S. Those who understand: knowledge growth in teaching. Educational Researcher, Washington, v. 15, n. 2, p. 4-14, 1986.

Disponível em: https://pdfs.semanticscholar.org/f29d/a5d8c806102bo6oe7669f67b5f9a55d8f7c4.pdf. Acesso em: 15 jun. 2020.

SOUZA, J. A. S. et al. Concepções de universidade no Brasil: uma análise a partir da missão das universidades públicas federais brasileiras e dos modelos de universidade. Revista Gestão Universitária na América Latina, v. 6, n. 4, 2013.

TERRAZZAN, E. A. et al. Configurações Curriculares em Cursos de Licenciatura e Formação Identitária de Professores. Revista Diálogo Educacional, v. 8, n. 23, 2008, p. 71-90.

ZABALZA, M. A. Competências docentes. In: CONFERÊNCIA PONTIFÍCIA UNIVERSIDAD JAVERIANA, 2005, Cali. Proceedings [...]. Cali: Pontificia Universidad Javeriana, 2005, p. 87-125.

ZANZINI, M.; TALLES, D.; TERRAZZAN, E. A. Saberes docentes em cursos de Licenciatura em Química: um estudo preliminar. In: ENCONTRO NACIONAL DE PESQUISA EM EDUCAÇÃO EM CIÊNCIAS, 10., 2015, Águas de Lindóia. Anais [...]. Águas de Lindóia/SP: ABRAPEC, 2015, p. 1-7.

Recebido: 04/06/2019 Aprovado: 20/12/2020 